\title{
ANÁLISE DA QUALIDADE DOS RECURSOS HÍDRICOS UTILIZADOS POR BANHISTAS EM PRESIDENTE EPITÁCIO-SP
}

\author{
ANALYSIS OF THE QUALITY OF WATER RESOURCES USED TO BATHERS \\ IN PRESIDENTE EPITÁCIO - SP
}

Matheus Consulo Novaes de Brito, Vinícius Marques Gomes, Daniel Ângelo Macena

Universidade do Oeste Paulista, Curso de Química Bacharelado, Presidente Prudente, São Paulo.

e-mail: novaesunoeste@hotmail.com.

RESUMO - A contaminação de regiões balneares é um fator preocupante em escala mundial. Afeta principalmente as áreas relacionadas à recreação no ambiente de praia. Os surtos das doenças associadas ocorrem em época de temporada, em que, aumenta-se o percentual de banhistas e a presença de depósitos de animais domésticos. Foram determinados os valores de $\mathrm{pH}$, Turbidez, DQO, DBO e análise microbiológica de amostras de água coletadas em diferentes períodos do Parque Figueiral em Presidente Epitácio. Os resultados apresentaram conformidade com o estabelecido pela CETESB que é o órgão regulamentador, exceto os resultados para Coliformes que foi classificado como imprópria para uso recreativo apresentando 1000 UFC/100 $\mathrm{mL}$ em mais de $20 \%$ do tempo. Portanto, ressalta-se a necessidade do constante monitoramento da água, garantindo melhores condições aos que fazem uso desses ambientes.

Palavras-chave: balneabilidade; qualidade da água; saúde pública.

Recebido em: 10/08/2017 Revisado em: 16/08/2017 Aprovado em: 24/08/2017
ABSTRACT - Contamination of bathing areas is a worrisome factor on a worldwide scale. It mainly affects areas related to recreation in the beach environment. Outbreaks of associated diseases occur during the season, in which the percentage of bathers increases and the presence of deposits of domestic animals. The values of $\mathrm{pH}$, Turbidity, COD, BOD and microbiological analysis of water samples collected in different periods of the Parque Figuiral in Presidente Epitácio were determined. The results were in compliance with the established by CETESB, which is the regulatory body, except for the results for Coliformes that was classified as unfit for recreational use with $1000 \mathrm{CFU} /$ $100 \mathrm{~mL}$ in more than $20 \%$ of the time. Therefore, the need for constant monitoring of water is emphasized, guaranteeing better conditions to those who use these environments.

Keywords: balneability; water quality; public health. 


\section{INTRODUÇÃO}

A crescente demanda em ocupação de zonas litorâneas é a principal causa da falta de qualidade da balneabilidade, uma vez que, ocorre intensa participação antrópica direta e indireta em ambientes que deveriam ser preservados. Além disso, a constante exploração de recursos naturais e os interesses econômicos envolvidos, tais como: a valorização de áreas litorâneas agregado ao investimento em modernização também contribuem com marcas negativas sobre a esse meio (AURELIANO, 2000).

De acordo com a definição apresentada pela Companhia Ambiental do Estado de São Paulo, (CETESB, 2011) balneabilidade "é a qualidade das águas destinadas à recreação de contato primário, sendo este entendido como o contato direto e prolongado com a água (natação, mergulho, esqui-aquático, etc.), onde a possibilidade de ingerir quantidades apreciáveis de água é elevada." O conceito de balneabilidade está relacionado à qualidade das águas destinadas ao banho, conforme expressa o adjetivo balneável.

A presença de bactérias nas águas está diretamente associada ao despejo impróprio de efluentes domésticos em decorrência da grande ocupação desses locais, principalmente em épocas de temporada (BRASIL, 2011). Isso acontece devido à deficiência ou a falta de estações de tratamento de esgoto e também pela contaminação dos córregos que desaguam no mar (NUNES, 2010). Além disso, acontecimentos raros tais como: a incidência de maré vermelha ou o imprevisto despejo de petróleo podem também tornar a região afetada inadequada para atividades recreativas de contato primário (BRASIL, 2011).

Outro aspecto importante a se considerar, são os lixos e outros resíduos lançados no solo, estes são carregados pela água da chuva até as praias, córregos e canais de drenagem, assim cooperam com acréscimo em microrganismos patogênicos e a consequente poluição desse ambiente aquático (BRASIL, 2011).

A contaminação de regiões balneares é um fator preocupante em escala mundial. Afeta principalmente as áreas relacionadas à recreação no ambiente de praia (SOARES, 2009). Os surtos das doenças associadas ocorrem em época de temporada, em que, aumenta-se o percentual de banhistas e a presença de depósitos de animais domésticos (MONTEIRO, 2013).

A contaminação dos banhistas por vírus, bactérias ou protozoários existentes na água causam doenças patógenas como a gastroenterite, hepatite $A$, cólera, etc. Além de transmitir a conjuntivite e doenças nas vias respiratórias. Afetam principalmente 
crianças e idosos ou pessoas com baixa imunidade (NUNES, 2010).

Ao ser constatado a contaminação da água por esses parasitas, o local passa a ser considerado um risco a saúde pública. Dessa forma, recomenda-se o isolamento da área que passa a ser improprio para banho (SILVA, 2011). Na areia das praias, por exemplo, já foram detectados vários organismos nocivos ao homem como S. stercoralis, Toxocara spp., A. lumbricoides e Ancilostomídeos (SOARES, 2009).

A doença respiratória febril aguda e as infecções gastrointestinais, nos olhos, ouvidos, cavidade nasal são as doenças mais comuns associadas à infecção por estes seres (SILVA apud ORGANIZAÇÃO MUNDIAL DA SÚDE, 2011).

Desse modo, este trabalho teve como objetivo analisar a água do balneário de Presidente Epitácio - SP (Parque Figueiral) para garantir se o índice de balneabilidade atende ao estabelecido pelo órgão fiscalizador, CETESB.

\section{METODOLOGIA}

Foram coletadas 1 amostra de água (mensal) do Parque Figueiral (Presidente Epitácio - SP) em períodos diferentes, sendo de Fevereiro a Junho de 2017. Por fim totalizou cinco amostras no fim do período, foi garantida a coleta no mesmo ponto controlado por Sistema de Posicionamento
Global - GPS. Todas as análises foram realizadas com base no procedimento instituído pela Associação Americana de Saúde Pública, através dos Standard methods for the examination of water and wastewater - 21a edição (2005), a fim de constatar se a qualidade da água a torna própria aos fins de balneabilidade.

Preservação das características físicas, químicas e biológicas até o laboratório.

De acordo com Wilde et al. (1999), os procedimentos de preservação e transporte das amostras são cruciais para evitar a contaminação e minimizar a alteração das propriedades destas. A fim de preservar as características físicas, químicas e biológicas das amostras, foram utilizadas as técnicas de refrigeração que, segundo a NBR ISO/IEC 17.025 (ABNT, 2001), trata-se de manter a amostra refrigerada entre $1^{\circ} \mathrm{C}$ e $4 \stackrel{\circ}{\circ} \mathrm{C}$, fazendo uso preferencialmente de barras de gelo reutilizáveis para resfriar a amostra para transporte.

Determinação da qualidade físicoquímica das amostras

Análise de $\mathrm{pH}$ - (Standard Methods $4500-\mathrm{H}+: 2)$

Com o aparelho devidamente iniciado, foi feita a calibração do pH-metro com solução tampão 7,0 e 4,0. Em seguida, foram transferidos $150 \mathrm{~mL}$ da amostra para um béquer de $250 \mathrm{~mL}$. Foi então retirado o eletrodo do recipiente com a solução de 
repouso KCL 3 Mol.L-1. Após este procedimento, o eletrodo foi lavado, com auxílio de uma pisseta, com jatos de água purificada e foi secado suavemente com papel macio absorvente. Na sequência, o eletrodo foi imerso na solução da amostra, agitou-se suavemente com movimentos circulares e, por fim, foi acionada a tecla de medição do $\mathrm{pH}$. Após um minuto, o resultado foi exibido no display do aparelho. O mesmo procedimento foi realizado para todas as amostras devido os diferentes períodos.

Determinação de turbidez - (Standard Methods - 2130-B)

Foram utilizados $15 \mathrm{~mL}$ de amostra em uma cubeta específica que acompanha o kit de ensaio, a mesma foi cuidadosamente tampada e limpa com papel absorvente macio para eliminação das possíveis manchas de água e/ou gordura e impressões digitais. $\mathrm{Na}$ sequência, o aparelho (marca Quimis modelo Q279P) foi devidamente iniciado conforme instruções do manual, utilizando as soluções tampão apropriadas e a cubeta foi então inserida no compartimento. Este compartimento foi devidamente fechado para o início da leitura. Por fim, o valor de Turbidez e a unidade em NTU (unidades nefelométricas de turbidez) foram exibidos no display do aparelho.

Análise microbiológica para Coliformes totais e E. coli (Standard Methods $-9222-B)$
Foi colocado o copo funil previamente flambado no porta filtro acoplado no funil e seguro com garra, posteriormente a membrana filtrante foi colocada no porta filtro, com a pinça previamente flambada e fria. Em seguida o frasco contendo a amostra foi agitado para a total homogeneização e então verteu $100 \mathrm{~mL}$ da amostra no filtro evitando respingo sobre as bordas superiores. Depois, foi ligada a bomba a vácuo para fazer a suç̧ão. Após a filtração da amostra, obrigatoriamente as paredes do copo (funil) foram lavadas três vezes com porções de $20 \mathrm{~mL}$ de água de diluição estéril para evitar a contaminação das amostras posteriores a serem filtradas. Seguidamente, aliviou-se o vácuo e foi retirado o funil de suporte para então ocorrer a transferência da membrana filtrante para placas de petri previamente preparadas contendo ágar Chromocult, deixando o lado quadriculado para cima, com o auxilio de uma pinça metálica flambada e fria. Todas as placas foram tampadas rapidamente após a transferência da membrana e incubadas invertida a $35^{\circ} \mathrm{C}$ durante $24 \pm 2$ horas. Após o período de incubação foi examinado o filtro realizando a contagem das colônias. Colônias vermelhas - salmão (Coliformes totais) e colônias azuis - pretas (E. coli).

Determinação da Demanda Química de Oxigênio (Standard Methods - 5220 - D) 
A partir da solução padrão de Hidrogenoftalato de potássio, equivalente a uma DQO de $1000 \mathrm{mg}-102$, foram preparadas soluções com diferentes concentrações $(5,10,20,50,100,200$ e 400 mg-102) para a realização da curva de calibração.

Em diferentes balões volumétricos foram adicionados os volumes da solução padrão de DQO e o restante da água purificada para completar $100 \mathrm{~mL}$.

Foram transferidas alíquotas de 2,50 $\mathrm{mL}$ de cada padrão (amostra ou água destilada) para o tubo de digestão previamente preparado com $1,50 \mathrm{~mL}$ de solução digestora e $3,50 \mathrm{~mL}$ da solução catalítica.

Após serem firmemente fechados os tubos de solução digestora, foi promovida a homogeneização do conteúdo dos tubos, colocando-os em um digestor (bloco aquecedor) a $150^{\circ} \mathrm{C}$ por 2 horas. $\mathrm{O}$ mesmo procedimento foi realizado com a amostra e uma prova em branco com água purificada.

Após a digestão, foram retirados os tubos do aparelho digestor e aguardou-se 30 minutos para resfriar os tubos. Por fim, foi realizada a leitura da absorbância em um espectrofotômetro no comprimento de onda $620 \mathrm{~nm}$, com o aparelho devidamente zerado pelo teste em branco, e, a partir dos valores obtidos, foi traçada a curva de calibração e a concentração da DQO nas amostras.

Determinação da Demanda Bioquímica de Oxigênio (Standard Methods $5210-B)$

Primeiramente foi estimado o valor para DBO através da obtenção do resultado de DQO (demanda química de oxigênio). Sabendo-se que a DBO é aproximadamente a metade da DQO obtida, podendo variar \pm $30 \%$ de acordo com a amostra.

Valores de DQO abaixo de $5.000 \mathrm{mg}$ devem ser multiplicado por 0,5, para valores entre 5.000 e 6.000 multiplica-se por 0,6, de 6.000 a 8.000 por 0,7 e $>8.000$ por 0,8 . 0 resultado da multiplicação foi considerado como a "DBO esperada", a partir deste, foi possível determinar a escala de trabalho para o aparelho Oxitop conforme a tabela 1. 
Tabela 1. Parâmetros para ensaio da Demanda Bioquímica de Oxigênio - DBO5,20.

\begin{tabular}{c|ccc} 
DBO esperada & VA & FEO & VT \\
\hline $0-40 \mathrm{mg} / \mathrm{L}$ & $425 \mathrm{~mL}$ & 1 & $432 \mathrm{~mL}$ \\
$0-80 \mathrm{mg} / \mathrm{L}$ & $358 \mathrm{~mL}$ & 2 & $365 \mathrm{~mL}$ \\
$0-200 \mathrm{mg} / \mathrm{L}$ & $243 \mathrm{~mL}$ & 5 & $250 \mathrm{~mL}$ \\
$0-400 \mathrm{mg} / \mathrm{L}$ & $147 \mathrm{~mL}$ & 10 & $164 \mathrm{~mL}$ \\
$0-800 \mathrm{mg} / \mathrm{L}$ & $88 \mathrm{~mL}$ & 20,1 & $95 \mathrm{~mL}$ \\
$0-2000 \mathrm{mg} / \mathrm{L}$ & $43,5 \mathrm{~mL}$ & 50,3 & $43,5 \mathrm{~mL}$ \\
$0-4000 \mathrm{mg} / \mathrm{L}$ & $17,7 \mathrm{~mL}$ & 100,5 & $22,7 \mathrm{~mL}$
\end{tabular}

Fonte: APHA (2005).

Nota: VA = Volume da Alíquota; FEO= Fator de escala do Oxitop; VT= Volume total na garrafa (A coluna do volume total corresponde ao volume da alíquota somado a quantidade total de nutrientes e sementes).

Foi adicionado com auxilio de uma micropipeta $1 \mathrm{~mL}$ de cada nutriente, Solução tampão de fosfato $1,5 \mathrm{~N}$, Solução de cloreto de amônio $0,71 \mathrm{~N}$, Solução de cloreto de cálcio $0,25 \mathrm{~N}$, Solução de sulfato de magnésio $0,41 \mathrm{~N}$, Solução de cloreto férrico $0,018 \mathrm{~N}$, respectivamente.

Em seguida, foi pipetado o volume de amostra conforme a tabela 1. Foram adicionados 2,0 $\mathrm{mL}$ de semente/inibidor; hidratada, solução heterogênea com farelos em suspensão, pois os mesmo fazem o transporte das bactérias. Possui inibidor de nitrificação. A solução foi mantida sob agitação constante. Na sequência, a barra magnética foi inserida dentro da garrafa. Foram colocadas 3 pastilhas de $\mathrm{NaOH}$ na chupeta de borracha. A chupeta foi cuidadosamente colocada na boca da garrafa, pois o contato do $\mathrm{NaOH}$ causa a perda total da amostra, devendo iniciar todo o procedimento após lavagem do frasco com agua corrente e detergente neutro.

Após o fechamento da garrafa com o oxitop, foi acionado o sistema de agitação na incubadora. Foram então pressionadas simultaneamente as teclas $\mathrm{M}$ e $\mathrm{S}$ por 2 segundos no sensor Oxitop, até o aparecimento do valor 00 no visor, indicando que o sistema foi zerado para ativar o registro, que se iniciou logo após 3 horas (tempo de estabilização do sistema para $\left.20^{\circ} \mathrm{C}\right)$.

Por fim, foi lido no visor do sensor Oxitop o valor encontrado, multiplicado pelo fator da escala Oxitop de acordo com a escala utilizada para a DBO esperada.

\section{RESULTADOS}

De acordo com Derisio (2007), a influência do $\mathrm{pH}$ sobre os ecossistemas aquáticos naturais dá-se diretamente devido a seus efeitos sobre a fisiologia das diversas 
espécies. O efeito indireto é muito importante, pois em determinadas condições de $\mathrm{pH}$ pode contribuir para a precipitação de elementos químicos tóxicos como metais pesados, ou podem exercer efeitos sobre as solubilidades de nutrientes. Com relação aos resultados de $\mathrm{pH}$, verificou-se valores de $\mathrm{pH}$ maiores que $7 \mathrm{em}$ todas as amostras coletadas.

Gráfico 1. Resultados de pH das cinco amostras analisadas

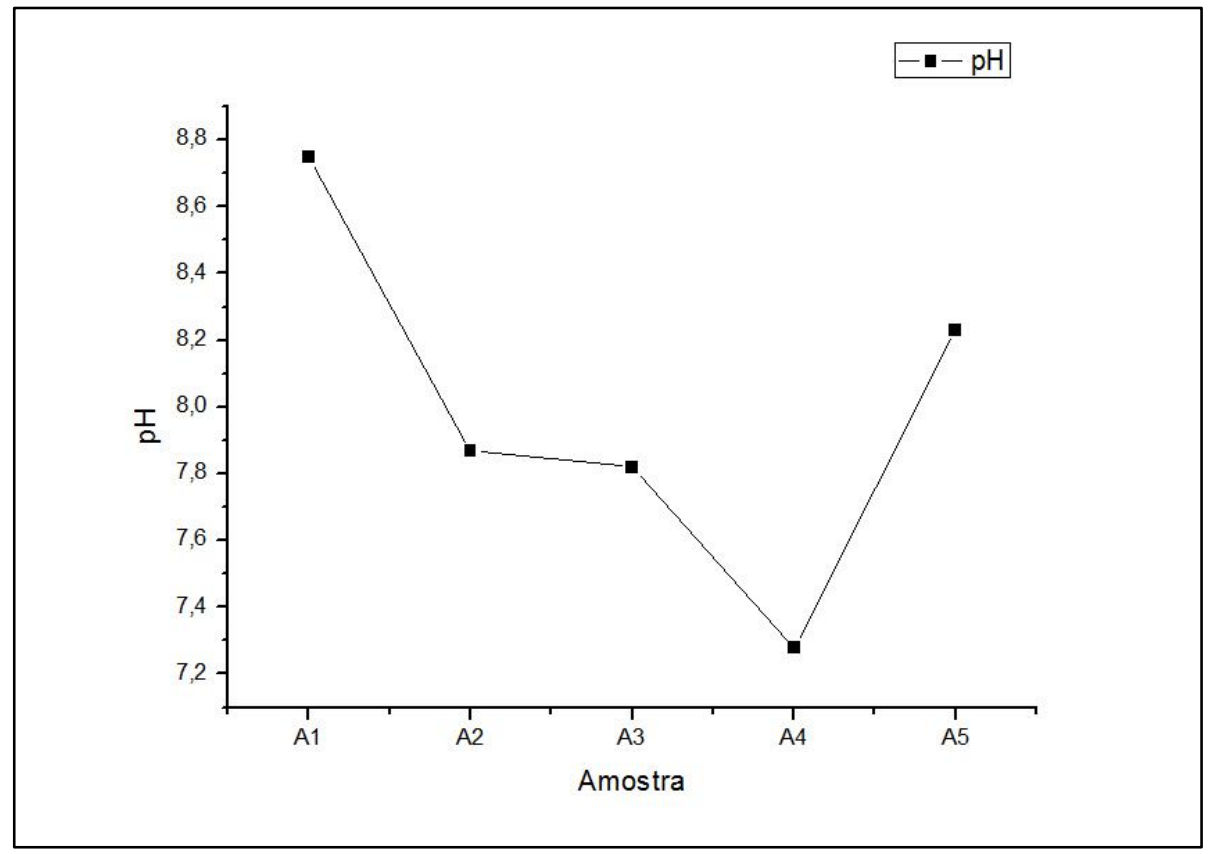

Fonte: Dados experimentais

A turbidez influi diretamente na utilização recreativa das águas, pois os banhistas tendem a buscar águas com maior transparência. Do ponto de vista sanitário, a turbidez poderá, quando elevada, afetar esteticamente os corpos d'água ou ainda encarecer o tratamento para os diversos usos. Outro fator a ser considerado, relaciona-se com a fauna e a flora, que poderão sofrer distúrbios em função da redução de penetração de luz (DERISIO, 2007). 
Gráfico 2. Resultados das análises de turbidez para as cinco amostras

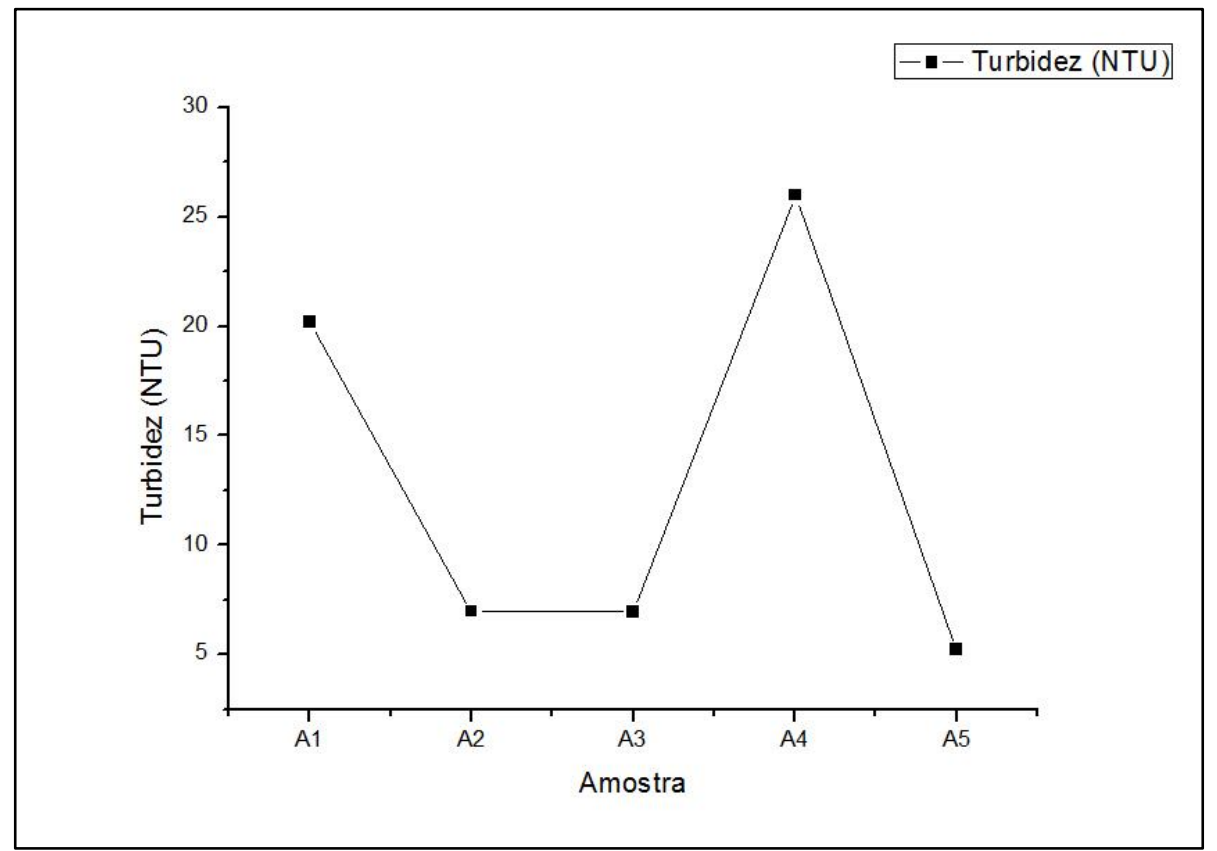

Fonte: Dados experimentais

Gráfico 3. Dados experimentais DQO e DBO das cinco amostras

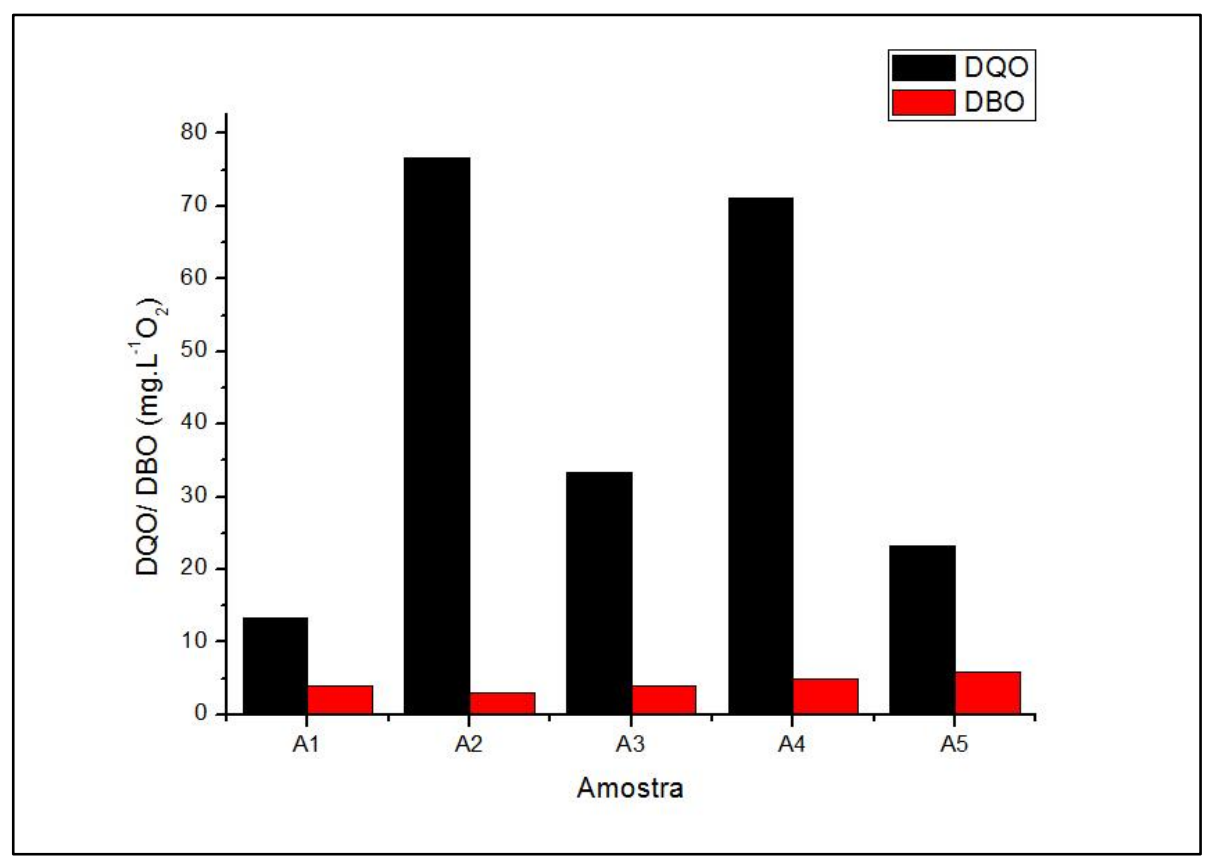

Fonte: Dados experimentais

Esteves et al. (2011) define que o oxigênio é um dos fatores mais importes na dinâmica e na caracterização dos ecossistemas aquáticos. Deste modo as análises de Demanda Química de Oxigênio e
Demanda Bioquímica de Oxigênio verificam, respectivamente, a quantidade de oxigênio necessária para dissolver toda matéria e a matéria orgânica no meio (SALDANHA, 2004). 
Os parâmetros microbiológicos são fundamentais para definir a qualidade sanitária de uma água, de um solo, de uma cultura ou outro elemento. As bactérias do grupo coliforme vêm sendo utilizadas como indicadores de poluição fecal desde o início do século XX (MITCHELL; ABEYSURIYA; ROSS, 2016). Os coliformes fecais são os indicadores de contaminação fecal tradicionalmente usado na Engenharia Sanitária e Ambiental e na legislação nacional do CONAMA (2000).

Gráfico 4. Dados experimentais para Coliformes totais e E. coli

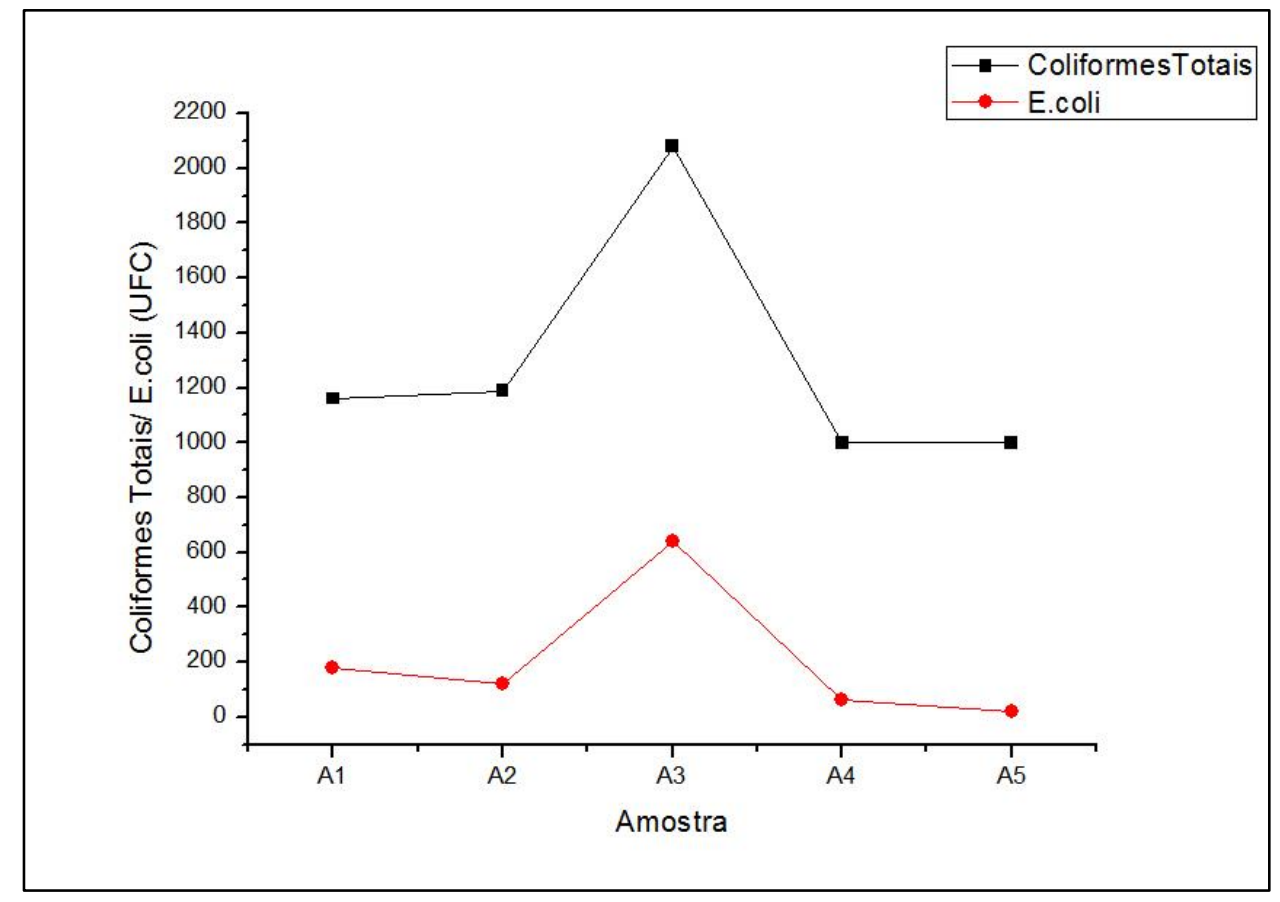

Fonte: Dados experimentais

\section{DISCUSSÃO}

Considerando os

valores experimentais de $\mathrm{pH}$, observou-se que todas as coletas apresentaram-se dentro dos limites estipulados pela resolução do CONAMA, que fixa os valores de $\mathrm{pH}$ entre $6 \mathrm{e}$ 9. Porém, com valores mais próximos do limite máximo de 9, evidenciando valores ligeiramente alcalinos, segundo referencia Derisio (2007), para valores de $\mathrm{pH}$ maior que 7. Fazendo uma analise temporal da Figura 1, observa-se o mesmo comportamento da serie analisada com valores médios variando de 7,28 a 8,75 , sendo que a amostra com menor aferido foi coletada durante período chuvoso. Deste modo, o valor do $\mathrm{pH}$ sofreu alterações durante os períodos de coleta, porém estas não são significantes para fins de balneabilidade, pois os valores apresentam conformidade com os padrões exigidos pela Resolução CONAMA $\mathrm{n}$ 응 
274/2000, fixado entre 6 e 9 (SANTOS et al., 2014).

No Gráfico 2, em relação a turbidez as amostras apresentaram variações que vão de 5,23 a 26 NTU, ressaltando que o maior valor aferido foi da amostra 4 coletada em período de precipitação pluvial, o que causa aumento das partículas sólidas e/ou matéria orgânica do meio, além de que a turbidez não pode indicar a qualidade da água, porém pode estar relacionada a presença de microrganismos patogênicos à saúde. Observou-se ainda que, mesmo com grande oscilação, os valores constatados apresentaram conformidade com a Resolução 274/2000, do CONAMA.

Os maiores valores aferidos na DQO e DBO ocorreram nas amostras 2 e 5, conforme - Gráfico 3. Quando analisados valores médios obtidos no plano geral das amostras coletadas, observa-se que, não ultrapassam o índice permitido pela Resolução 274/2000 do CONAMA, 5 mg.L-1 para um rio de classe II. Esta mesma resolução classifica as águas com DBO menor de que $4 \mathrm{mg} . \mathrm{L}-1$ como águas limpas e valores de DBO maior que $10 \mathrm{mg} . \mathrm{L}-1$ como águas poluídas.

Nas análises microbiológicas estiveram presentes os dois grupos de microrganismos avaliados no presente estudo, em todas as amostras, conforme exposto no Gráfico 4 e apresentou resultado igual ou superior a 1000 UFC para Coliformes totais, estando acima dos níveis aceitáveis de contaminação. Constatou-se ainda que as bactérias do grupo E. coli estiveram presentes em todas as amostras e, segundo o Ministério da Saúde, a E. coli é abundante em fezes humanas e de animais, sendo somente encontrada em esgotos, águas naturais e solos desde que tenham recebido contaminação fecal recente, proveniente de efluentes domésticos (BRASIL, 2006). Os resultados para a presença de E. coli indicaram que as amostras estão dentro do limite estabelecido pela Resolução Conama no $274 / 2000$ para um corpo de água de Classe II.

De acordo com a Cetesb (2014) as águas recebem uma classificação (Figura 1) conforme a balneabilidade apresentada através dos resultados analíticos, levando em consideração os resultados microbiológicos.

Para esta avaliação é crucial a determinação de critérios objetivos através de indicadores a serem monitorados $\mathrm{e}$ valores relacionados com padrões préestabelecidos, para então identificar o índice de balneabilidade do local estudado, observando se é favorável ou não. Podem-se definir as classes de balneabilidade como orientação aos usuários. 
Figura 1. Dados disponíveis pela CETESB para classificação de balneabilidade

\begin{tabular}{|c|c|c|c|c|}
\hline \multicolumn{2}{|c|}{ CATEGORIA } & $\begin{array}{l}\text { Coliforme Termotolerante } \\
\text { (UFCI100 mL) }\end{array}$ & Escherichia coli (UFCl100 mL) & Enterococos (UFCH100 mL) \\
\hline \multirow{3}{*}{ PRÓPRIA } & EXCELENTE & $\begin{array}{c}\text { Máximo de } 250 \text { em } 80 \% \text { ou } \\
\text { mais tempo }\end{array}$ & $\begin{array}{c}\text { Máximo de } 200 \text { em } 80 \% \text { ou } \\
\text { mais tempo }\end{array}$ & $\begin{array}{c}\text { Máximo de } 25 \text { em } 80 \% \text { ou } \\
\text { mais tempo }\end{array}$ \\
\hline & MUITO BOA & $\begin{array}{c}\text { Máximo de } 500 \text { em } 80 \% \text { ou } \\
\text { mais tempo }\end{array}$ & $\begin{array}{c}\text { Máximo de } 400 \text { em } 80 \% \text { ou } \\
\text { mais tempo }\end{array}$ & $\begin{array}{c}\text { Máximo de } 50 \text { em } 80 \% \text { ou } \\
\text { mais tempo }\end{array}$ \\
\hline & SATISFATÓRIA & $\begin{array}{l}\text { Máximo de } 1.000 \text { em } 80 \% \text { ou } \\
\text { mais tempo }\end{array}$ & $\begin{array}{c}\text { Máximo de } 800 \text { em } 80 \% \text { ou } \\
\text { mais tempo }\end{array}$ & $\begin{array}{c}\text { Máximo de } 100 \text { em } 80 \% \text { ou } \\
\text { mais tempo }\end{array}$ \\
\hline \multirow{2}{*}{\multicolumn{2}{|c|}{ |MPRÓPRIA }} & $\begin{array}{l}\text { Superior a } 1.000 \text { em mais } \\
\text { de } 20 \% \text { do tempo }\end{array}$ & $\begin{array}{l}\text { Superior a } 800 \text { em mais } \\
\text { de } 20 \% \text { do tempo }\end{array}$ & $\begin{array}{l}\text { Superior a } 100 \text { em mais } \\
\text { de } 20 \% \text { do tempo }\end{array}$ \\
\hline & & $\begin{array}{c}\text { Maior que } 2.500 \text { na última } \\
\text { medição }\end{array}$ & $\begin{array}{c}\text { Maior que } 2.000 \text { na última } \\
\text { medição }\end{array}$ & $\begin{array}{c}\text { Maior que } 400 \text { na última } \\
\text { mediçẫo }\end{array}$ \\
\hline
\end{tabular}

Fonte: CETESB (2014).

Levando em consideração a Figura 1 e relacionando os resultados para Coliformes a água do balneário aparece imprópria por apresentar-se superior a $1000 \mathrm{UFC} / 100 \mathrm{~mL}$ em mais de $20 \%$ do tempo. Fazendo a mesma análise comparativa para E. coli a água aparece na categoria própria e classificada como excelente por apresentar-se um máximo de 200 UFC/100 mL em $80 \%$ ou mais tempo.

\section{CONCLUSÃO}

Tendo como base a resolução CONAMA no 274/2000, é possível afirmar que a saúde e o bem-estar dos banhistas podem ser prejudicados pelas condições de balneabilidade das águas, sendo estas consideradas impróprias quando o valor obtido na amostragem for superior a 800 Escherichia coli ou 1000 Coliformes Totais por 100 mililitros de água (BRASIL, 2000).
Conclui-se que nenhuma amostra apresentou concentração superior a 800 UFC/100 mL para E. coli, não apresentando risco a saúde humana, enquanto que para Coliformes foi apresentado nos resultados um estado de alerta, pois no período de estudo não apresentou conformidade com o estabelecido pelo órgão regulamentador, expressando-se impropria para uso de contato direto e/ou recreação. Portanto, ressalta-se a necessidade do constante monitoramento da água, o que torna o presente estudo relevante e mostra o quão é importante à elaboração de mais pesquisas que agreguem informações em dados reais e específicos, e que sirvam de utilidade pública para que sejam tomadas decisões corretivas e preventivas, garantindo melhores condições aos que fazem uso desses ambientes. 


\section{REFERÊNCIAS}

ABNT. NBR ISO/IEC 17025. Rio de Janeiro: ABNT, 2001.

APHA - AMERICAN PUBLIC HEALTH ASSOCIATION. Standard Methods for the Examination of Water and Wastewater. 21. ed. Washington, DC: American Public Health Association, 2005. 1220p.

AURELIANO, J.T. Balneabilidade das praias de Pernambuco o núcleo Metropolitano. 2000. 113 f. Dissertação (Mestrado) - Universidade Federal de Pernambuco, Recife-PE, 2000.

BRASIL. Companhia Ambiental do Estado de são Paulo. Qualidade das Praias Litorânea no Estado de São Paulo. Relatório de Balneabilidade. São Paulo, 2011.

BRASIL. Fundação Nacional de Saúde. Manual prático de análise de água. 2. ed. rev. Brasília: Fundação Nacional de Saúde, 2006.

BRASIL. Resolução no 274 de 29 de novembro 2000. Dispõe sobre a balneabilidade dos corpos hídricos e a classificação das águas, doces, salobras e salinas. Diário Oficial [da] União, Brasília, 18 jun. 2000.

CETESB. Relatório de Qualidade das Águas Interiores do Estado de São Paulo, 2014. São Paulo: CETESB, 2014.

CETESB. Relatório de qualidade das praias litorâneas no estado de São Paulo. São Paulo: CETESB, 2011.

CONAMA. Resolução CONAMA, 2000. Brasília: Ministério da Habitação, Urbanismo e Meio Ambiente, 1988.

DERISIO, J. C. Introdução ao control de poluição ambiental. Oficina de Textos, 2007.

ESTEVES, F. A. et al. Fundamentos de limnologia. Rio de Janeiro: Interciência, 2011.
MITCHELL, C.; ABEYSURIYA, K.; ROSS, K. Making pathogen hazards visible: a new heuristic to improve sanitation investment efficacy. Waterlines, v. 35, n. 2, p. 163-181, 2016. https://doi.org/10.3362/1756-3488.2016.014

MONTEIRO, D. T. L. Comparação da qualidade bacteriológica da água marinha e da areia seca e molhada de duas praias do litoral leste do Ceará. 2013. 72f. Dissertação (Mestrado)- Universidade Federal do Ceará, Fortaleza, 2013.

NUNES, J. G. Avaliação microbiológica da areia e da água do mar na praia da Tapera e do Ribeirão da Ilha/SC relacionada ao cultivo de ostras e à balneabilidade. 2010. 71f. Monografia (Pós-Graduação) - Universidade do Sul de Santa Catarina, Florianópolis-SC, 2010.

SALDANHA, J. R. Monitoramento Ambiental de Efluentes Líquidos e Corpos Hídricos. Curitiba: [s.n.], 2004. Material didático da disciplina de Monitoramento Ambiental do Curso de Especialização em Engenharia Ambiental - CEFET-PR.

SANTOS, C. D. et al. Avaliação da eficiência da desinfecção mediante uso de cloro gás na ETE Insular. Florianópolis, 2014.

SILVA, R. M. B. Avaliação do efeito do estuário do Ave na qualidade das águas balneares do concelho de vila do conde. 2011. 92f. Dissertação (Mestrado) Universidade Fernando Pessoa, 2011.

SOARES, D. N. E. Bases microbiológicas e químicas da qualidade ambiental da água e areia da orla de Manguinhos- Serra, Espírito Santo, Brasil. 2009. 120f. Dissertação (Mestrado)- Centro Universitário Vila Velha, Universidade de Vila Velha, Vila Velha-ES, 2009.

WILDE, F. D. et al. National field manual for the collection of water-quality dataCollection of water samples: US Geological Survey Techniques of Water-Resources Investigations. v. 9, p. 49-52, 1999. 